\title{
Australasian Public Awareness and Belief in Conspiracy Theories: Motivational Correlates.
}

Mathew D. Marques ${ }^{1}$, Mathew Ling ${ }^{2}$, Matt N. Williams ${ }^{3}$, John R. Kerr ${ }^{4}$, and Jim McLennan ${ }^{1}$

${ }^{1}$ School of Psychology and Public Health, La Trobe University, Melbourne, Victoria 3086, Australia.

${ }^{2}$ Deakin University, Geelong, Australia, Misinformation Lab, School of Psychology.

${ }^{3}$ School of Psychology, Massey University, New Zealand.

${ }^{4}$ Department of Psychology, University of Cambridge, Cambridge, UK.

\section{Corresponding author:}

Mathew D. Marques, School of Psychology and Public Health, La Trobe University, Melbourne, Victoria 3086, Australia.

Online Article Accepted 17/02/2021 in Political Psychology

https://authorservices.wiley.com/author-resources/Journal-Authors/open-access/authorcompliance-tool.html

Marques, M. D., Ling, M., Williams, M. N., Kerr, J. R., \& McLennan, J. (2021). Australasian public awareness and belief in conspiracy theories: Motivational correlates. Political Psychology, 43(1), 177-198. doi: 10.1111/pops.12746

\section{Keywords}

conspiracy belief; conspiracy theories; motives; politics; psychology 


\begin{abstract}
Belief in conspiracies is not restricted to the fringe dwellers of society. International research suggests that such beliefs are quite common and that conspiracy theories may serve three basic psychological motives (i.e., epistemic, existential, and relational) for individuals. Yet, little is known about conspiracy theory awareness or belief in Australasia. We report the first large systematic investigation of system justifying motives using two nationally representative samples of Australians $(n=1,011)$ and New Zealanders $(n=754)$. Our findings show that almost all are aware of local and international conspiracies, the majority endorse one or more, and that all three psychological motives consistently relate to conspiracy belief, but not to awareness. In a series of hierarchical multiple regressions, we find that relational (i.e., increased anomie and disillusionment with the government) and existential motives (i.e., less trust in others and increased religiosity) are uniquely and relatively more important than epistemic needs (i.e., decreased analytic thinking) as predictors of increased local and international conspiracy belief. Findings are discussed in terms of the importance of understanding conspiracy theories as an ideological belief system that may function to serve underlying psychological motives.
\end{abstract}




\section{Introduction}

Research on understanding conspiracy theories has burgeoned in recent years. It suggests that many people in the United Kingdom and North America are not only familiar with conspiracy theories, but they also subscribe to them. For example, polling found one in five Britons think that harmful effects of vaccines are being kept hidden from the public (Waldersee, 2019), and two in five think that the UK government is hiding the truth about the number of immigrants living in the country (Moore, 2016). A study by Oliver and Wood (2014), using four nationally representative US samples, found that more than one in three people had heard of conspiracy theories relating to 'real' reasons for the 2001 World Trade Center attacks and the 2003 Iraq war, while nine out of 10 people had heard of the President Obama 'birther' conspiracy theory. Not only were these conspiracy narratives familiar to many Americans, but over 50 percent endorsed at least one of them, indicating that it is not just fringe groups who believe in social and political conspiracy theories.

Even so, very little is known about the prevalence of conspiracy belief in the Antipodes despite popular interest in local and international conspiracy theories among Australasian citizens (Crofts, 2016; Palmer, 2018). Conspiracy theories are lay beliefs (or explanations) about the cause, or concealment, of an event from the public, attributed to a secretive, illegitimate, hostile plot by a coalition or group of actors (e.g., Swami, ChamorroPremuzic, \& Furnham, 2010; van Prooijen, 2018). Compared to Australia, levels of belief are somewhat better understood in New Zealand, where estimates suggest nearly three in four people believe at least one conspiracy theory (Woolf, 2019). This recent survey of a sample of convenience found that more than forty percent of participants believed that the national rugby team was poisoned during the 1995 world cup held in post-apartheid South Africa, one in ten believed that NASA faked the moon landings, and almost one in fifteen agreed that world governments were hiding the presence of aliens. One relatively popular New Zealand 
conspiracy theory focuses on the Department of Conservation's use of 1080 poison (sodium fluoroacetate) to kill mammalian predators of native birds and plants. Opponents of the poison have claimed that the true purpose of 1080 is to contaminate wild sources of food, forcing citizens to depend on the government and corporations for sustenance (Slatherly, 2018). Another New Zealand conspiracy theory claims that the 2011 Canterbury earthquakes were triggered by the High Frequency Active Auroral Research Program (HAARP) — a US military ionosphere research program based in Alaska (Bridgeman, 2011).

Less is known about Australians' awareness of, and belief in, conspiracy theories other than the apparent persistence of several high-profile local narratives. For example, one based on events from over 50 years ago at the height of the cold war challenges the official narrative that Australia's $17^{\text {th }}$ Prime Minister (Harold Holt) drowned while swimming, claiming he was in fact taken away in a Chinese submarine (Frame, 2005). Another enduring narrative posits that Phar Lap, an extremely successful and popular racehorse in Australia during the early $20^{\text {th }}$ century, died as a result of poisoning by US gangsters while racing overseas (Reason, 2009). More recently, there have been conspiracy theories related to emerging technologies. For example, former Labor Prime Minister Kevin Rudd suggested that a subsequent Liberal National government conspired with Rupert Murdoch's News Corporation to sabotage his political party's design for a super-fast national broadband service (Koziol, 2019). Another is that a future 5G telecommunications network will cause serious illnesses such as cancer and that there is a cover up of medical evidence (Zappone, 2019). Both of these claims have apparently gained traction in New Zealand (Strongman, 2019). These are all examples of large-scale public cases where there is a degree of uncertainty surrounding the information, whereby individuals and communities search for meaning in what may be unrelated or random events. 
While historical, sporting, and technological conspiracies feature prominently in local discourse, there are also pernicious narratives circulating related to recent mass shooting crimes in both Australia and New Zealand. These suggest that shootings were false flag events orchestrated by government agencies to justify restriction of gun ownership (Dentith, 2019; Karp \& Tovey, 2019). At present, what is known about the nature and prevalence of conspiracy theories in both countries involves a mix of popular anecdotes, media accounts, and a small number of limited research investigations (e.g., Wilson \& Rose, 2014).

\section{A motivational account of conspiracy belief}

Although it is well established that a substantial minority of the general public believe conspiracy theories, the factors that produce belief in conspiracy theories remain unclear. In a monological belief system framework (Goertzel, 1994), it is assumed that belief in any one conspiracy theory will be correlated with belief in others, given the capacity of conspiracy theories to support one another. For example, belief that the government is covering up medical risks from the development of a 5G network may be easier to develop if one already believes that that the government is also covering up medical risks of vaccination. However, a monological account has been critiqued as limited, and it has been suggested that belief in conspiracies may form a more complex worldview with multiple dimensions (e.g., Franks, Bangerter, Bauer, Hall, \& Noort, 2017). Douglas, Sutton, and Cichocka (2017) have proposed a framework based on the motivational basis of system justification processes to understand the complex nature of conspiracy belief. Adapted from Jost, Ledgerwood, and Hardin (2008), system justification theory can help organize the factors related to conspiracy belief into three basic human motives: an epistemic motive to understand the world, to increase knowledge, certainty, and accuracy; an existential motive to reduce threat and to maintain a safe and stable environment; and the more recently proposed relational motive (also referred to as a social motive) to maintain valued interpersonal relationships and a 
positive image of the self and in-group. There is growing evidence for this motivational basis of conspiracy belief (Douglas et al., 2017), but a notable absence in understanding the relative and unique importance of these motives, in addition to a lack of systematic research in Australasia on belief in conspiracies.

Given the apparent role of some conspiracy theories in mobilizing aggressive opposition to public health campaigns like vaccination (Jolley \& Douglas, 2014a) and to climate change mitigation (Jolley \& Douglas, 2014b), it is critical to understand the degree to which motives underly and sustain conspiracy belief (Goertzel, 2010). In the present study we test this psychology of conspiracy theories framework (Douglas et al., 2017) to examine the unique and relative relationships between exemplars of epistemic, existential, and relational motives alongside conspiracy awareness and belief, using samples from Australia and from New Zealand. Our objectives are two-fold. Firstly, we aim to describe the levels of awareness and belief in conspiracies using local (Australasian) and international narratives. To date this has been understudied and not investigated systematically. Second, we assess the extent to which both awareness and conspiracy belief are related to pre-existing and common measures used in the study of conspiracy theories so as to establish the unique and relative importance of these three underlying system justification motives; we propose these motives are more important in explaining belief than awareness, consistent with a motivational account of conspiracy belief.

We begin with a review of how awareness and belief has previously been found to be related to selected exemplars of epistemic (i.e., analytic style), existential (i.e., trust, political and religious ideologies), and relational motives (i.e., anomie and disillusionment with government). The psychological motivations examined here are a limited subset of factors underlying belief in conspiracies. However, they illustrate theoretically and empirically established constructs representing these three system justification motives (Douglas et al., 
2019), consistent with the psychology of conspiracy theories framework (Douglas et al., 2017). Following each account, we propose specific hypotheses relating to both conspiracy awareness and belief. Thereafter, we present a set of overall aims and hypotheses.

\section{Epistemic motive: analytic style}

Belief in conspiracies may satisfy a need for reducing uncertainty by helping individuals find meaning in complex or random events (Douglas et al., 2017). There is some evidence that conspiratorial thinking is a heuristic used to make sense of complex random and low probability events (Kovic \& Füchslin, 2018), although other findings suggest that perceptions of meaning instead of randomness and conspiracy belief are unrelated (Dieguez, Wagner-Egger, \& Gauvrit, 2015). Writing on American politics over half a century ago, historian Richard Hofstadter (1964) detailed the paranoid style, suggesting that it was a mentality predisposing a minority of the population to see conspiracies in society. More recent studies have investigated whether conspiracy belief may serve this epistemic need for sensemaking by investigating its relationships with analytic style and analytic thinking - two related but distinct constructs. On the one hand, analytic style encompasses a preference or motivation for elaborated forms of thinking and judgement as compared to a preference for automatic or effortless problem solving, and can be construed as a motivation (Cacioppo \& Petty, 1982). On the other hand, analytic thinking can be thought of as the ability to override an intuitive, but incorrect, response with a correct response (e.g., Pennycook, Cheyne, Seli, Koehler, \& Fugelsang, 2012).

In a series of studies examining correlates and predictors of belief in conspiracy theories, Swami, Voracek, Stieger, Tran, and Furnham (2014) showed that a preference for analytic style is associated with decreased belief in conspiracy theories, and that engaging in analytic thinking can attenuate belief in conspiracies. Other studies also support this view that 
analytic thinking (i.e., a tendency to reflect about problems that at first blush seem to have an intuitive - obvious - answer), as compared with intuitive processing, is related to decreased conspiracy belief (Barron et al., 2018; Ståhl \& van Prooijen, 2018). These and other findings suggest that belief in conspiracies may express an ideological belief system based around a conspiracy-promoting, and sustaining, way of thinking: for example, a conspiratorial mindset has been linked to a tendency to infer causal relationships between unrelated events (Brotherton \& French, 2014). Studies also show that increased education is related to lower belief in conspiracies (e.g., Goertzel, 1994; Oliver \& Wood, 2014; Ståhl \& van Prooijen, 2018), suggesting that lower levels of belief may be related to increased preference for an analytic, rather than an intuitive, way of thinking (van Prooijen, 2017).

These findings suggest that analytic thinking may be an important predictor of lower levels of conspiracy belief, but it is unclear how this is related to awareness of conspiracies. Research investigating analytic thinking and the overclaiming of knowledge of people and events suggested a moderate negative relationship between the two (Pennycook \& Rand, 2018). However, as overclaiming involves recognizing familiarity between false and genuine events, it may be the case that analytic thinking is only weakly related or unrelated to awareness of a conspiracy theory, given that many conspiracy narratives are widespread in public discourse.

Hypothesis 1: Analytic thinking will be negatively correlated with conspiracy belief.

\section{Existential motive: trust}

A key element of conspiracy theories is their distrustful representation, or suspicion of, others and groups, which has been proposed to be evolutionarily adaptive to reduce threats and maintain a safe environment (van Prooijen \& Van Vugt, 2018). Trust is distinct from distrust (or mistrust), which can coexist and be distinguished empirically, and has different 
antecedents and consequents (Lewicki, McAllister, \& Bies, 1998). Consistent with Lewicki et al. (1998) we view trust as the "positive expectations regarding another's conduct", to be distinguished from distrust (or mistrust) which is the "negative expectations regarding another's conduct" (p. 439). A major focus in the conspiracy theory literature has been on institutional trust/mistrust, with empirical research mostly examining positive and negative expectations of government and authority. For example, studies show that decreased trust in authorities is related to increased belief in conspiracies (Abalakina-Paap, Stephan, Craig, \& Gregory, 1999; Swami et al., 2010). Furthermore, research has shown that exposure to general conspiracy theories lead to decreased trust in government institutions (Einstein \& Glick, 2015), and that governmental distrust can persist for some time after exposure to government conspiracy theories (Kim \& Cao, 2016). Our focus is on trust in specific others, which can include specific trust in authorities and government, but is distinct from both general forms of institutional and dispositional trust (i.e., in general others; McKnight \& Chervany, 2001).

Interpersonal trust/mistrust in others can incorporate entities such as government agencies, but often encompasses targets beyond authorities. Research has investigated relationships between increased/decreased interpersonal dis/trust with increased belief in conspiracy theories - but little is known about familiarity or awareness with these narratives. Seminal research by Goertzel (1994) showed there was a moderate negative relationship between belief and a person's level of trust in their neighbors, relatives, and the police. Importantly, this relationship appears to be robust across various conceptualizations of conspiracy belief (Lantian, Muller, Nurra, \& Douglas, 2016). Understanding both the levels and relationships between these concepts is important given evidence that trust is important in civic engagement (e.g., Van Ingen \& Bekkers, 2015) and democratic actions such as voting (e.g., Abrams \& Travaglino, 2018). 
Hypothesis 2: Trust in others will be negatively correlated with conspiracy belief.

\section{Existential motive: political and religious ideologies}

Governments and authorities are often the focus of conspiracy theories, so it is reasonable to expect that political ideologies may be related to conspiracy belief. An ideology is a cognitive structure of organized of ideas, attitudes and values around an abstract theme (Converse, 2006). In addition to reducing feelings of uncertainty and generalized threat, selfidentifying along an ideological continuum may function in part to satisfy people's needs for social inclusion and belonging, as individuals identify with others who hold similar values (Caprara et al., 2017). Research suggests that belief in conspiracies is stronger for those who identify as politicly conservative (Mancosu, Vassallo, \& Vezzoni, 2017), or for those with conservative ideologies such as Right-Wing Authoritarianism (RWA) or Social Dominance Orientation (SDO; e.g., Bruder, Haffke, Neave, Nouripanah, \& Imhoff, 2013). In addition, conspiracies involving figures or groups on the other side of politics are often found to be more believable (Enders \& Smallpage, 2019). For instance, Miller, Saunders, and Farhart (2016) found that not only do individuals report conspiracy belief consistent with ideological partisanship (i.e., greater levels of belief about those on the other side of the political divide), but that high political knowledge and low trust exacerbate this effect, particularly for conservatives. However, other research suggests that conspiracy belief is more pronounced for those at the extremes of political self-placement on a right to left continuum (van Prooijen, Krouwel, \& Pollet, 2015), or that it is related to support with minor single-issue parties (Uscinski \& Parent, 2014).

Political self-placement using a unidimensional construct from left to right, or conservative to progressive, is related to various political and psychological differences (Jost, 2006). Researchers have, however, called for a more nuanced conceptualization 
differentiating economic and social dimensions (Feldman \& Johnston, 2014). Recent research in several US samples found that both social and economic conservatism was positively associated with increased belief in a specific conspiracy theory (i.e., climate change is a hoax) and conspiratorial ideation (van der Linden, Panagopoulos, Azevedo, \& Jost, 2020). Conceptualizing political ideology across these two dimensions may be useful, given that a single dimension may not provide adequate fidelity to capture the nature of political beliefs; it is also consistent with ideological belief as organized around two orthogonal dimensions relating to social and economic conservatism, as suggested to overlap with RWA and SDO, respectively (Duckitt, 2001). Specifically, research has shown that Authoritarianism is a stronger predictor of conspiracism as compared with SDO (Bruder et al., 2013), especially for pro-establishment conspiracies as they may threaten established social order and authorities (Wood \& Gray, 2019). Therefore, it is important to investigate the role of this multidimensional conceptualization of political ideology with conspiracy belief in Australasia, given the societal focus of many narratives.

Belief in conspiracies is not the only ideology employed to reduce the uncertainty caused by random large-scale events and allow individuals to find meaning in attributing the causes to hidden or unseen forces (Oliver \& Wood, 2014). Religious beliefs may also serve to mitigate existential uncertainty (Barber, 2011). Research examining both belief in conspiracies and belief in, or personal importance of, a supernatural or spiritual higher being, or organized system of faith and worship, suggests a positive relationship between the two (Mancosu et al., 2017; Ståhl \& van Prooijen, 2018). It may be that religious ideology not only functions to reduce uncertainty, but also to serve an existential motive of experiencing and maintaining a felt security and control over the unknown.

Hypothesis $3 a$ : Those who identify as more politically conservative, as compared to progressive, will report greater conspiracy belief. 
Hypothesis $3 b$ : Social political ideology, will be more strongly related to conspiracy belief than economic political ideology.

Hypothesis 4: Those who report greater level of importance in religion or spirituality will report greater levels of conspiracy belief.

\section{Relational motive: anomie and disillusionment with government}

The relationship between belief in conspiracies and anomie — defined by French sociologist Émile Durkheim (1897/1951) as a sense of individual discomfort about declining values, law, and social order in society — has also been investigated. While it is unclear whether it is a reaction against, or the result of, perceived regulatory social controls of society, this feeling of alienation is negatively related to interpersonal trust. Increased levels of anomie have been associated with increased levels of general conspiracy thinking (Brotherton, French, \& Pickering, 2013) and specific belief in conspiracy theories (Abalakina-Paap et al., 1999; Goertzel, 1994), including those related to authorities and minority out-groups (Wagner-Egger \& Bangerter, 2007). Recent research argues that anomie may be a mechanism by which exposure to conspiracies facilitate antisocial behavior such as everyday petty crime (Jolley, Douglas, Leite, \& Schrader, 2019). This suggests that social processes such as alienation and personal unrest in understanding the social world are heightened by conspiracy theories (Douglas et al., 2017).

Associated with views about the decline of society, disillusionment may reflect a relational motive beyond institutional mistrust, where disappointment is felt due to a failure to meet expectations or feeling cheated or deceived by the government. Overall, exposure to conspiracy theories has been shown to lead to increased disillusionment but may be context dependent. For example, following exposure to climate conspiracies, disillusionment with climate scientists increased (Jolley \& Douglas, 2014a), and disillusionment with those 
responsible for manufacture and administration of vaccines increased following exposure to vaccine conspiracies (Jolley \& Douglas, 2014b). However, exposure to several government conspiracies did not lead to increased disillusionment with the government (Jolley et al., 2019).

Hypothesis 5: Levels of anomie and disillusionment with the government will be positively correlated with conspiracy belief.

\section{Overall Aims and Hypotheses}

The aim of the present study is to describe the levels of conspiracy awareness and belief in Australasians, for both local and international conspiracy narratives. In addition, we will examine how epistemic, existential, and relational motives uniquely relate to belief in, and awareness of conspiracies as a test of the underlying psychological motives after accounting for general demographic predictors. Mere awareness of conspiracies is unlikely to relate to these motives, however, given that less is known about what relates to conspiracy awareness, we frame this part of our investigation with the following research question and final, overall, hypothesis:

Research Question 1: To what extent are epistemic, existential, and relational factors associated with awareness of conspiracies?

Hypothesis 6: Psychological motives will better predict levels of conspiracy belief as compared with awareness.

\section{Method}

\section{Participants and Procedure}

Data were collected between 9 and 20 September 2019, using the data collection company Dynata (dynata.com). Before beginning the survey, potential adult participants were 
asked their age, gender, and state of residence (or region for New Zealand). Interlocking quotas, based on the latest available estimates for Australia (2018 Q4; Australian Bureau of Statistics, 2019a) and New Zealand (2019 Q2; Stats NZ, 2019), were used to target 1,000 and 750 potential Australian and New Zealand adult participants and ensure that the sample was representative on these demographic variables. Potential participants were directed to an online Qualtrics survey by Dynata, but those who did not meet the quota (i.e., their specific age-group, gender, and location were already full) were screened out prior to the survey (Australia $n=1,284$; New Zealand $n=816$ ). Participants with incomplete surveys (drop outs), and those with invalid responses indicated by a combination of short overall survey duration (e.g., below the $5^{\text {th }}$ percentile for length of time taken), failed attention checks (e.g., agreement with the statements such as "I can levitate buildings with my mind"), and invalid text responses (e.g., gibberish in open text responses for analytic thinking items) were excluded during the data collection (Australia $n=105$; New Zealand $n=43$ ) and the panel was resampled to meet quotas. ${ }^{1}$ In total there were 1,015 and 758 eligible Australian and New Zealand participants, respectively. Demographic information is presented in Table 1.

The sample was representative of the Australian population in terms of age, gender, and geographic location due to the interlocking quotas. We applied sample weights based on age and gender to both samples, due to a slight overrepresentation of females and older people in Australia, and males and younger people in New Zealand. ${ }^{2}$ The New Zealand sample was similar to the population with respect to geographic location, whereas there was a modest over representation in the Australian sample of Metropolitan/Urban dwellers.

\footnotetext{
${ }^{1}$ Re-analysis of all hypotheses involving these excluded cases did not change the pattern or interpretation of any results.

${ }^{2}$ Weights were applied to adjust representativeness for several reasons. Firstly, quotas based on estimates sometimes resulted in low cell numbers, especially in New Zealand where we sampled 16 regions. Secondly, our quotas were also based on age by decade (e.g., age 30-39). Lastly, in the final days of data collection we removed the age by decade restrictions on quotas in New Zealand to reach our targets (3\% of the sample).
} 
Overall, both samples were more highly educated than the population on university education attainment and there was a modest difference in level of reported average annual income for both samples. Both the Australian and New Zealand samples were more educated (Australian Bureau of Statistics, 2019b; Stats NZ, 2018a) than national census data. Nearly $45 \%$ of our sample reported achieving a university education versus approximately $22 \%$ nationally, and similarly almost $49 \%$ of the New Zealand sample as compared to approximately $25 \%$ nationally. In terms of personal income the reported median income in our samples were slightly lower for Australians and similar for New Zealanders as compared to national estimates (Australian Bureau of Statistics, 2018; Stats NZ, 2018b). Australian median personal income was $\$ 55,432$ vs $40-49,000$ in our sample, whereas Zealand median personal income was $\$ 51,527$ vs $\$ 40-49,000$ in our sample; with the mode selected was $\$ 20$ 29,000 .

Eligible adult participants (i.e., who met the quota), responded to the scales and items in the order presented below. Following the completion of these materials, participants reported on demographics. This research was approved by the Human Ethics Committee of La Trobe University (reference HEC19372). Data and syntax for all analyses can be found here https://osf.io/29zbp/

[INSERT Table 1. Demographic characteristics APPROXIMATELY HERE]

\section{Materials}

\section{Conspiracy awareness and belief}

Awareness of, and belief in eight international conspiracy theories were assessed with statements developed for this study and adapted from existing conspiracy research investigating belief in specific conspiracy theories (Douglas, Sutton, Callan, Dawtry, \& Harvey, 2016; Jolley \& Douglas, 2014b; Lewandowsky, Gignac, \& Oberauer, 2013; Oliver \& 
Wood, 2014). Example items included, “The American moon landings were faked" and "Scientists are creating panic about climate change because it is in their interests to do so". Participants also reported their awareness of, and belief in seven local conspiracy theories, sampled by the researchers to capture recent and historically known narratives from newsprint and internet sources, whose content differed between the Australian and New Zealand surveys. Example items for New Zealand included "The New Zealand All Blacks were deliberately poisoned before their 1995 rugby World Cup Final against South Africa" and "The Christchurch mosque shootings were orchestrated with the intent of restricting gun laws in New Zealand”. Example items for Australia included “Australia's 17th Prime Minister, Harold Holt, did not drown at sea but was kidnapped and taken away in a Chinese submarine" and "Legendary racehorse Phar Lap was poisoned by US gangsters to get rid of him because he was too successful".

Prior to each conspiracy participants were asked "Have you heard before?" and provided the response option of Yes or No. Following, they were asked to indicate their level of agreement with the narrative using a 5-point Likert scale (1=Strongly disagree, 2=Disagree, 3=Neither, 4=Agree, 5=Strongly agree). Conspiracy belief was conceptualized as the average of agreement with the seven local (Australia $\alpha=.80$; New Zealand $\alpha=.81$ ), and eight international items (Australia $\alpha=.86$; New Zealand $\alpha=.84$ ) for each country. In the Supplementary documents we report method and results of a multi-sample confirmatory factor analysis across countries that suggests equivalence on the international conspiracy belief items across Australia and New Zealand demonstrating high construct reliability (>.99; see Supplementary Table 1). ${ }^{3}$

\section{Trust}

\footnotetext{
${ }^{3}$ In the Supplementary materials, we also report endorsement of conspiracy theories as any level of agreement with each narrative, and provide a methodological comparison against our primary analyses relating to belief in conspiracy theories.
} 
Trust was assessed using a three-item scale adapted from previous research (Goertzel, 1994; Wagner-Egger \& Bangerter, 2007). Participants were asked how much they could trust their neighbors, the police, and the justice system on a 7-point scale $(1=$ Not at all; $7=$ Very $m u c h$ ). Item responses were averaged to create a scale, and reliability (Australia $\alpha=.67$; New Zealand $\alpha=.73$ ) was comparable with previous studies (Lantian et al., 2016; Wagner-Egger \& Bangerter, 2007).

\section{Anomie}

Anomie was assessed using a three-item scale adapted from Srole (1956) also used in previous research on conspiracy theories (Brotherton et al., 2013). Participants indicated their level of agreement with statements such as, "In spite of what some people say, the condition of the average person is getting worse, not better", using a 7-point Likert scale ( $1=$ Strongly disagree $7=$ Strongly agree). Item responses were averaged to create a scale, and reliability (Australia $\alpha=.70$; New Zealand $\alpha=.63$ ) was deemed acceptable and was higher than previous studies (Brotherton et al., 2013; Goertzel, 1994).

\section{Disillusionment with Government}

Disillusionment with the Australian (or New Zealand) Government was assessed using a four-item scale adapted from (Jolley \& Douglas, 2014b). Participants reported their level of agreement with statements such as, "I have given up on the New Zealand (Australian) government", using a 7-point Likert scale (1=Strongly disagree; 7=Strongly agree). Item responses were averaged to create a scale, and reliability (Australia $\alpha=.92$; New Zealand $\alpha=.91$ ) was higher than previous studies (Jolley \& Douglas, 2014b).

\section{Analytic Thinking}

Analytic thinking was assessed using an shortened form (three of the four items) of the cognitive reflection test (Thomson \& Oppenheimer, 2016). Participants were asked to 
provide text response to three questions such as "If you're running a race and you pass the person in second place, what place are you in?" (intuitive answer: first; correct answer: second). Correct answers were scored a 1 (incorrect as 0 ) and summed to give a total score ranging from 0 to 3 where higher scores indicated greater analytic thinking and lower scores intuitive thinking.

\section{Results and Discussion}

\section{Awareness of Conspiracies}

Almost all Australians (95.1\%) and New Zealanders (97.2\%) indicated they had heard of one or more conspiracies from the full list of 15 . Specific to the seven local conspiracies, $77.7 \%$ and $71.8 \%$ of Australians and New Zealanders had heard of one or more, respectively (see Supplementary Table 2 for results); Both samples reported low awareness of local conspiracies (Australia: $M=2.00, S D=1.70$; New Zealand: $M=1.74, S D=1.51$ ). New Zealanders and Australians were most aware of sporting conspiracy theories, with one in two Australians having heard of the Phar Lap Racehorse conspiracy, and over $60 \%$ of the 1995 New Zealand All Blacks poisoning conspiracy. As shown in Figure 1, these well-known conspiracies were also the most agreed with $(31 \%$ of Australians and $32 \%$ of New Zealanders either agreed or strongly agreed with these).

\section{[INSERT FIGURE 1 APPROXIMATELY HERE]}

Consistent with previous research we included a fabricated conspiracy narrative in order to help assess the validity of our findings. An updated version of the Compact Fluorescent Light Bulb conspiracy (Oliver \& Wood, 2014) was used: “The New Zealand (Australian) government is mandating the switch to LED light bulbs because such lights 
make people more obedient and easier to control". ${ }^{4}$ As compared with other local conspiracies, awareness (7-9\%) was considerably lower than any other local narrative, and frequency of agreement ranged between 5-7\% for New Zealanders and Australians, respectively. Given awareness and agreement were low, it may suggest that responses to the conspiracies are genuine. It may also suggest that those who agreed with this conspiracy theory may be receptive to believing unheard of conspiracy theories.

\section{[INSERT FIGURE 2 APPROXIMATELY HERE]}

Australasians were more aware of international conspiracy narratives, as compared to local narratives. From the eight presented, most Australians (90.9\%) and New Zealanders $(93.2 \%)$ indicated they had heard of one or more. The most familiar conspiracy for New Zealanders (82\%) and Australians (75\%) was that the American moon landings were faked (see Figure 2 and Supplementary Table 3 for results). New Zealanders indicated having heard significantly more international conspiracy theories $(M=4.62, S D=2.39)$ as compared with Australians $\left(M=4.27, S D=2.37 ; d=-0.15, \mathrm{CI}_{95}[-.24,-.05]\right)$, however Australians were more likely to believe them $\left(d=-0.13, \mathrm{CI}_{95}[-.23,-.04]\right)$.

\section{Belief in conspiracies}

Descriptive statistics of local and international conspiracy belief for Australians and New Zealanders, along with correlations between conspiracy belief and psychological motives are presented in Table 2. Both samples were below the neutral mid-point for local and international conspiracy belief. For both countries, the pattern and strength of correlations were similar and generally in the small to medium range (Cohen, 1992). Relationships between local and international belief with the motives were consistent with existing research. That is, increased belief in conspiracies was associated with lower levels of

\footnotetext{
${ }^{4}$ Neither government is mandating this switch.
} 
trust in others (Goertzel, 1994; Lantian et al., 2016) and decreased analytic thinking (Barron et al., 2018; Ståhl \& van Prooijen, 2018; Swami et al., 2014), as well as increased levels of anomie (Abalakina-Paap et al., 1999; Goertzel, 1994), increased disillusionment with the national government (Jolley \& Douglas, 2014a, 2014b), in addition to a preference for conservative economic and social political ideology (Mancosu et al., 2017) and increased importance of religion and spirituality (Ståhl \& van Prooijen, 2018). Conversely, conspiracy awareness had generally no to very small relationships with psychological motives (see Supplementary Table 4 for correlations). These results lend initial support to our hypotheses and research questions, specifically that psychological motives will better predict levels of conspiracy belief as compared with awareness.

\section{[INSERT TABLE 2 APPROXIMATELY HERE]}

\section{Local awareness and belief in conspiracies}

A series of hierarchical multiple regressions were used to examine the extent that our constructs assessing psychological motives predict awareness and belief in conspiracies. We acknowledge that due to the design the results are correlational but have used this approach in combination with relative importance analyses (Tonidandel \& LeBreton, 2011) to look at the unique and relative (rescaled as a percentage) contributions of correlates with conspiracy theory awareness or belief, after controlling for demographic factors. Separate models for both local conspiracy theory awareness and belief for each sample are presented in turn, followed by a single model predicting international conspiracy belief across both samples (see Supplementary materials for analyses of the equivalence of conspiracy belief across Australia $[\mathrm{AU}]$ and New Zealand [NZ]). The results for the analyses predicting belief in conspiracies are presented below for local (see Table 3) and international (see Table 4) 
narratives, whereas for awareness are summarized in text (see Supplementary Tables 5 and 6 for results).

Demographic variables were weak predictors of awareness of local conspiracy theories explaining between $2.7-4.3 \%$ of the variance (see Supplementary Table 5 for results). Men and those who reported living in a rural or remote location were significantly more likely to report having heard local conspiracies. Younger New Zealanders were also more aware of conspiracies. The addition of the other psychological correlates increased explanatory power of the model, but only accounted for $4.9-5.4 \%$ of the variance in awareness. Results suggested that awareness of local conspiracy theories was related with greater disillusionment in their national government, and with increased religion or spiritual importance for New Zealanders.

In contrast to awareness, demographic variables more strongly associated with conspiracy belief explaining between $6.1-13.3 \%$ of the variance (see Table 3 for results). Rescaled relative weight analysis (RRWA) indicated that in these models, younger people reported significantly higher levels of belief $\left(\mathrm{RRWA}_{\mathrm{AU}}=39.89 \%\right.$; $\left.\mathrm{RRWA}_{\mathrm{NZ}}=10.83 \%\right)$. The addition of psychological correlates accounted for an additional 15.7-22.4\% of the variance, with almost $30 \%$ of the variance in conspiracy belief being explained by these models. In sum, increased levels of belief was most strongly and uniquely associated with those reporting higher levels of anomie $\left(\mathrm{RRWA}_{\mathrm{AU}}=13.93 \%\right.$; $\left.\mathrm{RRWA}_{\mathrm{NZ}}=24.33 \%\right)$, disillusionment in the government $\left(\mathrm{RRWA}_{\mathrm{AU}}=16.64 \%\right.$; $\left.\mathrm{RRWA}_{\mathrm{NZ}}=16.83 \%\right)$, importance of religion and/or spirituality $\left(\mathrm{RRWA}_{\mathrm{AU}}=8.11 \%\right.$; RRWA $\left.\mathrm{NZ}=20.75 \%\right)$, and lower levels of analytic thinking $\left(\mathrm{RRWA}_{\mathrm{AU}}=7.33 \% ; \mathrm{RRWA}_{\mathrm{NZ}}=6.00 \%\right)$. Decreased trust in others was only a significant correlate of increased levels of belief for New Zealanders ( $R$ RWA $\left.A_{\mathrm{NZ}}=10.63 \%\right)$. 


\section{International awareness and belief in conspiracies}

Turning to awareness of international conspiracies, once again demographic variables were weak correlates explaining between 1.6-2.0\% of the variance (see Supplementary Table 6 for results). Apart from Australian men who indicated greater awareness of international conspiracy theories, demographic variables were not significant correlates. The addition of psychological motives did increase the explanatory power of the model of awareness, but similar to local conspiracies only led to a modest $R^{2}$ of $8.6-9.0 \%$. For both countries less trust in others, lower analytic thinking, and greater social political conservatism was associated with increased awareness of international conspiracy theories. Specific to New Zealanders, those who were more disillusioned with the national government reported greater awareness, and for Australians, those with greater levels of anomie were more likely to report having heard international conspiracies.

Given the equivalence of belief in international conspiracy theories across Australia and New Zealand we report one set of analyses, collapsed across countries. Demographic predictors explained a small portion of the variance in belief of international conspiracies (8.4\%; see Table 4 for results). Overwhelmingly age was an important predictor, with younger people $(\mathrm{RRWA}=21.34 \%$ ), and those who lived in Rural or Remote areas as compared to those in Metropolitan and Urban areas (RRWA $=0.57 \%$ ), reported greater levels of conspiracy belief. The addition of psychological motives suggested that almost one-third of the variance in international conspiracy theory endorsement $\left(R^{2}=29.1 \%\right)$ could be explained by demographic and motivational correlates. In order of relative and unique importance, it was individuals with higher levels of anomie (RRWA=27.38\%), decreased trust in others (RRWA=15.92\%), higher levels of disillusionment in government $(\mathrm{RRWA}=12.84 \%)$, and importance of religion and/or spirituality (RRWA $=10.43 \%$ ) who reported significantly higher levels of conspiracy belief related to international narratives. 
Smaller significant contributions to increased belief in international conspiracies were social political conservatism $(\mathrm{RRWA}=4.51 \%)$ and decreased levels of analytic thinking $(\mathrm{RRWA}=3.82 \%)$, with economic political conservatism not being a significant predictor. While analyses indicated equivalence in conspiracy beliefs across countries, they also suggested that belief that scientists are creating a climate change panic for their self-interest may be distinctive from the other narratives, inconsistent with a monological account of conspiracy belief.

\section{[INSERT TABLE 4 APPROXIMATELY HERE]}

\section{General Discussion}

Our first aim was to systematically examine levels of awareness and conspiracy belief in Australasia. We found that for both New Zealanders and Australians there was a high level of awareness of conspiracy theories, especially international ones. In addition, international conspiracy theories were both more heard of and more highly endorsed, and Australians, overall, believed and endorsed more conspiracies than their trans-Tasman neighbors in New Zealand. While mean levels suggested Australians believed more in conspiracy theories, relationships between conspiracy belief in international conspiracy narratives were consistent across both countries. Conspiracy theories appear to be quite familiar to Australasians, with most people reporting they believed one or more, suggesting beliefs were not 'aberrant'.

In our examination of how epistemic, existential, and relational motives were related to both awareness and belief in conspiracies, we found that they are consistently associated with belief, and less so with awareness of conspiracies - thus, supporting our first five hypotheses and final overall hypothesis. Our models predicting belief in specific local and international conspiracy theories explained almost a third of the variance predominately from general psychological motives and factors, and less so with demographic predictors. It is not 
only important that we accounted for a substantial proportion of the variance in conspiracy belief using general psychological motivations, but also that these motivations were not able to account for one-tenth of the variance in conspiracy awareness. On the whole this suggests that conspiracy belief may function to serve distinct basic human motives consistent with a systems justification account (Jost et al., 2008), whereas awareness does not seem to have the same function. Belief in specific conspiracy theories may function akin to a heuristic, helping individuals find meaning in large and random complex events, given the negative relationship between belief and analytic thinking (Kovic \& Füchslin, 2018). While this epistemic motive was a significant unique correlate of conspiracy belief, existential and relational functions may be more experientially meaningful. Relative weight analyses suggest, at least for our chosen motivational exemplars, that relational motives (anomie and disillusionment with the government), as well as some existential motives (trust and religious ideologies) seem to be relatively more important in predicting conspiracy belief than an epistemic need (analytical thinking). Our results reflect the complex nature of conspiracy belief and indicate that multiple existential and relational motives are key in understanding why and who believe in conspiracy theories.

Conspiracy theories are characterized by reference to clandestine actions, depicting distrustful powerful groups. As compared with the role of analytic thinking, increased levels of anomie, disillusionment with the government were all stronger unique correlates of increased belief in conspiracy theories. Consistent with previous research (e.g., Goertzel, 1994; Jolley \& Douglas, 2014b), these associations likely reflect increased alienation with society and feelings of being let down by the national government by those with increased levels of conspiracy belief. In addition, we found that those with lower levels of trust in their neighbors, the police, and justice system reported greater levels of conspiracy belief (Goertzel, 1994; Lantian et al., 2016). These relational and existential motives, which may be 
conceptually distinct but in practice may have considerable overlap as indicated by the intercorrelations between these constructs, suggest conspiracy belief being associated with broad social and political disengagement. It may be that conspiracy belief functions to reduce uncertainty and maintain a safe and stable environment as well as defend against a personal threat to one's image and that of their group.

Increased importance in religion or spirituality was associated with greater conspiracy belief, consistent with previous research (Mancosu et al., 2017). This suggests that a role of belief is to reduce uncertainty, similar to a function that organized faith systems may serve. In addition, our research also reported the first known examination of a multidimensional political ideology alongside conspiracy belief. While small, but significant, relationships were found between both economic and social political ideology and conspiracy belief, together in a model it was the latter that was more meaningful. Given social conservatism is associated Authoritarianism, whereas economic conservatism is associated with Social Dominance (Duckitt, 2001), these findings are consistent with previous findings that the former is a stronger predictor of conspiracism (Bruder et al., 2013), but diverge slightly from recent research in US samples showing equal importance of these forms of ideology with belief in a specific conspiracy and conspiracism more generally (van der Linden et al., 2020). In our samples, belief in conspiracy theories may function to reduce threat more for those motivated to maintain authority and social order.

Finally, as predicted there were weaker relationships between epistemic, existential, and relational motives and conspiracy theory awareness. Having heard of local conspiracy theories was linked with a greater sense of being let down or feeling cheated by the government, and lower levels of analytic thinking was associated with higher levels of belief in international conspiracies. However, it is unlikely this effect is due to overclaiming knowledge (Pennycook \& Rand, 2018), given that the recall of a conspiracy theory is 
independent of its unproven nature. Furthermore, those who identified as more socially conservative were also more aware of international conspiracies, which may suggest some individuals are better able to recall narratives that challenge social order and authority, and offer explanations for large and complex random events.

\section{Limitations and Future Directions}

A strength of our approach was that we reported findings on two samples, both nationally representative on age, gender, and region. At the same time there were some limitations to the present study due to our method and sampling. Both samples comprised of non-random online panels that may not be representative of other characteristics. For instance, our samples reported higher incomes and were more educated than the general population, factors associated with decreased belief in conspiracy theories (e.g., Douglas et al., 2016). While we controlled for these and other demographic variables in order to test the relationship of motives with conspiracy belief in line with system justification theory, the generalizability of our effects to individuals who do not participate in online panels may be difficult to assess. Due to the cross-sectional design, caution should be exercised about causal interpretations; some of the reported relationships may be the result of causal effects in the opposite direction to those hypothesized, or the result of third variables. This is especially important, given recent focus not only on whether levels of conspiracy belief are due to underlying motives, but also whether these motives satisfy belief in conspiracy theories. For instance, experimental studies have begun to address issues of causality around how exposure to conspiracy theories change underlying motives such as increased sense of powerlessness (Jolley \& Douglas, 2014b) and reduce conspiracy belief when control is affirmed (van Prooijen \& Acker, 2015). While our study was confirmatory in nature (i.e., we have reported how our sample was determined, any data exclusions, and all analyses conducted to test these hypotheses), it was not preregistered (Nosek, Ebersole, DeHaven, \& Mellor, 2018). 
Future research should examine whether conspiracy theories satisfy underlying psychological motives (Douglas et al., 2017) with the use of large scale longitudinal surveys. Furthermore, while research on the psychology of conspiracy theories has grown rapidly in the past decade (Douglas et al., 2019), future research should continue to seek to understand the impact of these narratives on political engagement (e.g., voting, civic engagement), health and wellbeing (e.g., vaccination, public health), science denial (e.g., climate change, 5G phone networks), and prejudice (e.g., minority group attitudes). Emerging research also suggests that cognitive training of around misinformation, including conspiracy theories, may reduce the perceived reliability and persuasiveness of fake news articles, which may provide a method to redress the epistemic motivation (Roozenbeek \& van der Linden, 2019), however it may also be important to focus on existential or relational needs. This study involved a selective choice of conspiracies and motivational exemplars, that while conceptually distinct in practice may overlap somewhat. Future research may benefit from additional predictors of belief in conspiracies such as collective narcissism (Cichocka, Marchlewska, Golec de Zavala, \& Olechowski, 2016), and intergroup threat (van Prooijen \& Song, 2020) which may be important in differentiating between local and international narratives. Extending previous research on conspiracy endorsement as motivated reasoning (Miller et al., 2016), examining how general political awareness might attenuate, exacerbate, or change how motives are associated with both awareness and belief in conspiracy theories may be important for future research. Our systematic examination of belief in local and international conspiracies was important in describing levels of awareness and belief in Australasia, and suggests the importance of underlying psychological motives in understanding conspiracy belief.

In conclusion, awareness of conspiracy theories in New Zealand and Australia is common, and most people believe in at least one local or international conspiracy. There is little evidence to suggest that belief in conspiracy theories is reserved for the fringe dwellers 
of society. Our results suggest that basic human motives may give rise to these extraordinary beliefs for many ordinary people.

\section{ACKNOWLEDGEMENTS}




\section{References}

Abalakina-Paap, M., Stephan, W.G., Craig, T., \& Gregory, W.L. (1999). Beliefs in conspiracies. Political Psychology, 20(3), 637-647. doi:10.1111/0162-895X.00160

Abrams, D., \& Travaglino, G.A. (2018). Immigration, political trust, and Brexit-Testing an aversion amplification hypothesis. British Journal of Social Psychology, 57(2), 310326. doi:10.1111/bjso.12233

Australian Bureau of Statistics. (2018). Characteristics of Employment, Australia, August 2018. Retrieved from https://www.abs.gov.au/ausstats/abs@.nsf/mf/6333.0

Australian Bureau of Statistics. (2019a). Australian Demographic Statistics, Dec 2018. Retrieved from https://www.abs.gov.au/AUSSTATS/abs@.nsf/Lookup/3101.0Main+Features1Dec\% 202018?OpenDocument

Australian Bureau of Statistics. (2019b). Education and Work, Australia, May 2019. Retrieved from http://www.abs.gov.au

Barber, N. (2011). A cross-national test of the uncertainty hypothesis of religious belief. Cross-Cultural Research, 45(3), 318-333. doi:10.1177/1069397111402465

Barron, D., Furnham, A., Weis, L., Morgan, K.D., Towell, T., \& Swami, V. (2018). The relationship between schizotypal facets and conspiracist beliefs via cognitive processes. Psychiatry research, 259, 15-20. doi:10.1016/j.psychres.2017.10.001

Bridgeman, S. (2011). Chemtrails blaze path for conspiracy theorists. Retrieved from https://www.nzherald.co.nz/lifestyle/news/article.cfm?c_id=6\&objectid=10771790

Brotherton, R., \& French, C.C. (2014). Belief in conspiracy theories and susceptibility to the conjunction fallacy. Applied Cognitive Psychology, 28(2), 238-248. doi:10.1002/acp.2995

Brotherton, R., French, C.C., \& Pickering, A.D. (2013). Measuring belief in conspiracy theories: The generic conspiracist beliefs scale. Frontiers in psychology, 4, 279. doi:10.3389/fpsyg.2013.00279

Bruder, M., Haffke, P., Neave, N., Nouripanah, N., \& Imhoff, R. (2013). Measuring individual differences in generic beliefs in conspiracy theories across cultures: Conspiracy Mentality Questionnaire. Frontiers in psychology, 4, 225. doi:10.3389/fpsyg.2013.00225

Cacioppo, J.T., \& Petty, R.E. (1982). The need for cognition. Journal of personality and social psychology, 42(1), 116. doi:10.1037/0022-3514.42.1.116 
Caprara, G.V., Vecchione, M., Schwartz, S.H., Schoen, H., Bain, P.G., Silvester, J., . . Kirmanoglu, H. (2017). Basic values, ideological self-placement, and voting: A crosscultural study. Cross-Cultural Research, 51(4), 388-411. doi:10.1177/1069397117712194

Cichocka, A., Marchlewska, M., Golec de Zavala, A., \& Olechowski, M. (2016). 'They will not control us': Ingroup positivity and belief in intergroup conspiracies. British Journal of Psychology, 107(3), 556-576. doi:10.1111/bjop.12158

Converse, P.E. (2006). The nature of belief systems in mass publics (1964). Critical review, 18(1-3), 1-74. doi:10.1080/08913810608443650

Crofts, C. (2016). Aussie Conspiracy Theories people still believe. National Geographic. Retrieved from https://www.nationalgeographic.com.au/australia/aussie-conspiracytheories-people-still-believe.aspx

Dentith, M.R.X. (2019). The Christchurch terrorism conspiracy theories are not just false. They're dangerous. The Spinoff. Retrieved from https://thespinoff.co.nz/society/2003-2019/the-christchurch-terrorism-conspiracy-theories-are-not-just-false-theyredangerous/

Dieguez, S., Wagner-Egger, P., \& Gauvrit, N. (2015). Nothing happens by accident, or does it? A low prior for randomness does not explain belief in conspiracy theories. Psychological science, 26(11), 1762-1770. doi:10.1177/0956797615598740

Douglas, K.M., Sutton, R.M., Callan, M.J., Dawtry, R.J., \& Harvey, A.J. (2016). Someone is pulling the strings: Hypersensitive agency detection and belief in conspiracy theories. Thinking \& Reasoning, 22(1), 57-77. doi:10.1080/13546783.2015.1051586

Douglas, K.M., Sutton, R.M., \& Cichocka, A. (2017). The psychology of conspiracy theories. Current directions in psychological science, 26(6), 538-542. doi:10.1177/0963721417718261

Douglas, K.M., Uscinski, J.E., Sutton, R.M., Cichocka, A., Nefes, T., Ang, C.S., \& Deravi, F. (2019). Understanding conspiracy theories. Political Psychology, 40, 3-35.

Duckitt, J. (2001). A dual-process cognitive-motivational theory of ideology and prejudice. In Advances in experimental social psychology (Vol. 33, pp. 41-113): Elsevier.

Durkheim, E. (1897/1951). Suicide : a study in sociology. Glencoe, Ill.: Free Press.

Einstein, K.L., \& Glick, D.M. (2015). Do I think BLS data are BS? The consequences of conspiracy theories. Political Behavior, 37(3), 679-701. doi:10.1007/s11109-0149287-z 
Enders, A.M., \& Smallpage, S.M. (2019). Polls, Plots, and Party Politics: Conspiracy Theories in Contemporary America. In J.E. Uscinski \& J.M. Parent (Eds.), American conspiracy theories (pp. 187-200): Oxford University Press.

Feldman, S., \& Johnston, C. (2014). Understanding the determinants of political ideology: Implications of structural complexity. Political Psychology, 35(3), 337-358. doi:10.1111/pops. 12055

Frame, T.R. (2005). The life and death of Harold Holt: Allen \& Unwin Crows Nest, NSW.

Franks, B., Bangerter, A., Bauer, M.W., Hall, M., \& Noort, M.C. (2017). Beyond "monologicality"? Exploring conspiracist worldviews. Frontiers in psychology, 8, 861. doi:10.3389/fpsyg.2017.00861/full

Goertzel, T. (1994). Belief in conspiracy theories. Political Psychology, 731-742.

Goertzel, T. (2010). Conspiracy theories in science. EMBO reports, 11(7), 493-499. doi:10.1038/embor.2010.84

Hofstadter, R. (1964). The paranoid style in American politics and other essays. In R. Hofstadter (Ed.), (pp. 3-40). Cambridge, MA: Harvard University Press.

Jolley, D., \& Douglas, K.M. (2014a). The effects of anti-vaccine conspiracy theories on vaccination intentions. PloS one, 9(2), e89177. doi:10.1371/journal.pone.0089177

Jolley, D., \& Douglas, K.M. (2014b). The social consequences of conspiracism: Exposure to conspiracy theories decreases intentions to engage in politics and to reduce one's carbon footprint. British Journal of Psychology, 105(1), 35-56. doi:10.1111/bjop.12018

Jolley, D., Douglas, K.M., Leite, A.C., \& Schrader, T. (2019). Belief in conspiracy theories and intentions to engage in everyday crime. British Journal of Social Psychology, 58, 534-549. doi:10.1111/bjso.12311

Jost, J.T. (2006). The end of the end of ideology. American psychologist, 61(7), 651. doi:10.1037/0003-066X.61.7.651

Jost, J.T., Ledgerwood, A., \& Hardin, C.D. (2008). Shared reality, system justification, and the relational basis of ideological beliefs. Social and Personality Psychology Compass, 2(1), 171-186. doi:10.1111/j.1751-9004.2007.00056.x

Karp, P., \& Tovey, J. (2019). Pauline Hanson suggests Port Arthur massacre was a government conspiracy. The Guardian. Retrieved from https://www.theguardian.com/australia-news/2019/mar/28/pauline-hanson-suggestsport-arthur-massacre-was-a-government-conspiracy 
Kim, M., \& Cao, X. (2016). The impact of exposure to media messages promoting government conspiracy theories on distrust in the government: Evidence from a twostage randomized experiment. International Journal of Communication, 10, 20.

Kovic, M., \& Füchslin, T. (2018). Probability and conspiratorial thinking. Applied Cognitive Psychology, 32(3), 390-400. doi:10.1002/acp.3408

Koziol, M. (2019). Turnbull rebukes Rudd's 'insane conspiracy theory' he trashed NBN for Murdoch. Retrieved from https://www.smh.com.au/politics/federal/turnbull-rebukesrudd-s-insane-conspiracy-theory-he-trashed-nbn-for-murdoch-20190111-p50qwl.html

Lantian, A., Muller, D., Nurra, C., \& Douglas, K.M. (2016). Measuring belief in conspiracy theories: Validation of a French and English single-item scale. International Review of Social Psychology, 29(1), 1-14. doi:10.5334/irsp.8

Lewandowsky, S., Gignac, G.E., \& Oberauer, K. (2013). The role of conspiracist ideation and worldviews in predicting rejection of science. PloS one, 8(10), e75637. doi:10.1371/journal.pone.0075637

Lewicki, R.J., McAllister, D.J., \& Bies, R.J. (1998). Trust and distrust: New relationships and realities. Academy of management Review, 23(3), 438-458. doi:10.5465/amr.1998.926620

Mancosu, M., Vassallo, S., \& Vezzoni, C. (2017). Believing in conspiracy theories: Evidence from an exploratory analysis of Italian survey data. South European Society and Politics, 22(3), 327-344. doi:10.1080/13608746.2017.1359894

McKnight, D.H., \& Chervany, N.L. (2001). Trust and distrust definitions: One bite at a time. In Trust in Cyber-societies (pp. 27-54): Springer.

Miller, J.M., Saunders, K.L., \& Farhart, C.E. (2016). Conspiracy endorsement as motivated reasoning: The moderating roles of political knowledge and trust. American Journal of Political Science, 60(4), 824-844. doi:10.1111/ajps.12234

Moore, P. (2016). Little British believe in outlandish conspiracy theories. Retrieved from https://yougov.co.uk/topics/politics/articles-reports/2016/05/27/conspiracies

Nosek, B.A., Ebersole, C.R., DeHaven, A.C., \& Mellor, D.T. (2018). The preregistration revolution. Proceedings of the National Academy of Sciences, 115(11), 2600-2606. doi:10.1073/pnas.1708274114

Oliver, J.E., \& Wood, T.J. (2014). Conspiracy theories and the paranoid style (s) of mass opinion. American Journal of Political Science, 58(4), 952-966. doi:10.1111/ajps.1 2084 
Palmer, S. (2018). New Zealand's top conspiracy theories. Newshub. Retrieved from https://www.newshub.co.nz/home/new-zealand/2018/01/new-zealand-s-topconspiracy-theories.html

Pennycook, G., Cheyne, J.A., Seli, P., Koehler, D.J., \& Fugelsang, J.A. (2012). Analytic cognitive style predicts religious and paranormal belief. Cognition, 123(3), 335-346. doi:10.1016/j.cognition.2012.03.003

Pennycook, G., \& Rand, D.G. (2018). Who falls for fake news? The roles of bullshit receptivity, overclaiming, familiarity, and analytic thinking. Journal of personality. doi:10.1111/jopy.12476

Reason, M. (2009). Phar Lap : A True Legend. Melbourne, Australia: Museum Victoria.

Roozenbeek, J., \& van der Linden, S. (2019). The fake news game: actively inoculating against the risk of misinformation. Journal of Risk Research, 22(5), 570-580. doi:10.1080/13669877.2018.1443491

Slatherly, D. (2018). 1080 activism: Going down the conspiracy 'wormhole'. Retrieved from https://www.newshub.co.nz/home/rural/2018/08/1080-activism-going-down-theconspiracy-wormhole.html

Srole, L. (1956). Social integration and certain corollaries: An exploratory study. American sociological review, 21(6), 709-716. doi:10.2307/2088422

Ståhl, T., \& van Prooijen, J.-W. (2018). Epistemic rationality: Skepticism toward unfounded beliefs requires sufficient cognitive ability and motivation to be rational. Personality and Individual Differences, 122, 155-163. doi:10.1016/j.paid.2017.10.026

Stats NZ. (2018a). 2018 Census totals by topic - national highlights. Retrieved from https://www.stats.govt.nz/information-releases/2018-census-totals-by-topic-nationalhighlights

Stats NZ. (2018b). Labour market statistics (income): June 2018 quarter. Retrieved from https://www.stats.govt.nz/information-releases/household-income-and-housing-coststatistics-year-ended-june-2018

Stats NZ. (2019). Subnational population estimates: At 30 June 2019 (provisional).

Retrieved from https://www.stats.govt.nz/information-releases/subnationalpopulation-estimates-at-30-june-2019-provisional

Strongman, S. (2019). Inside the anti-5G movement. Retrieved from https://www.rnz.co.nz/news/in-depth/392613/inside-the-anti-5g-movement 
Swami, V., Chamorro-Premuzic, T., \& Furnham, A. (2010). Unanswered questions: A preliminary investigation of personality and individual difference predictors of 9/11 conspiracist beliefs. Applied Cognitive Psychology, 24(6), 749-761. doi:10.1002/acp.1583

Swami, V., Voracek, M., Stieger, S., Tran, U.S., \& Furnham, A. (2014). Analytic thinking reduces belief in conspiracy theories. Cognition, 133(3), 572-585. doi:10.1016/j.cognition.2014.08.006

Thomson, K.S., \& Oppenheimer, D.M. (2016). Investigating an alternate form of the cognitive reflection test. Judgment and Decision making, 11(1), 99-113.

Tonidandel, S., \& LeBreton, J.M. (2011). Relative importance analysis: A useful supplement to regression analysis. Journal of Business and Psychology, 26(1), 1-9. doi:10.1007/s 10869-010-9204-3

Uscinski, J.E., \& Parent, J.M. (2014). American conspiracy theories: Oxford University Press.

van der Linden, S., Panagopoulos, C., Azevedo, F., \& Jost, J.T. (2020). The paranoid style in American politics revisited: An ideological asymmetry in conspiratorial thinking. Political Psychology. doi:10.1111/pops.12681

Van Ingen, E., \& Bekkers, R. (2015). Generalized trust through civic engagement? Evidence from five national panel studies. Political Psychology, 36(3), 277-294. doi:10.1111/pops.12105

van Prooijen, J.-W. (2017). Why education predicts decreased belief in conspiracy theories. Applied Cognitive Psychology, 31(1), 50-58. doi:10.1002/acp.3301

van Prooijen, J.-W. (2018). The Psychology of Conspiracy Theories: Milton : Routledge. van Prooijen, J.-W., \& Acker, M. (2015). The influence of control on belief in conspiracy theories: Conceptual and applied extensions. Applied Cognitive Psychology, 29(5), 753-761. doi:10.1002/acp.3161

van Prooijen, J.-W., Krouwel, A.P., \& Pollet, T.V. (2015). Political extremism predicts belief in conspiracy theories. Social Psychological and Personality Science, 6(5), 570-578. doi:10.1177/1948550614567356

van Prooijen, J.-W., \& Song, M. (2020). The cultural dimension of intergroup conspiracy theories. British Journal of Psychology. doi:10.1111/bjop.12471

van Prooijen, J.-W., \& Van Vugt, M. (2018). Conspiracy theories: Evolved functions and psychological mechanisms. Perspectives on psychological science, 13(6), 770-788. doi:10.1177/1745691618774270 
Wagner-Egger, P., \& Bangerter, A. (2007). La vérite est ailleurs: corrélats de l'adhésion aux théories du complot. Revue internationale de psychologie sociale, 20(4), 31-61.

Waldersee, V. (2019). Which science-based conspiracy theories do Britons believe?

Retrieved from https://yougov.co.uk/topics/science/articles-reports/2019/04/25/which$\underline{\text { science-based-conspiracy-theories-do-britons }}$

Wilson, M.S., \& Rose, C. (2014). 15 The role of paranoia in a dual-process motivational model of conspiracy belief. In J.-W.v. Prooijen \& P.A.M.v. Lange (Eds.), Power, politics, and paranoia: Why people are suspicious of their leaders (pp. 273-291). Cambridge, UK: Cambridge University Press.

Wood, M.J., \& Gray, D. (2019). Right-wing authoritarianism as a predictor of proestablishment versus anti-establishment conspiracy theories. Personality and Individual Differences, 138, 163-166. doi:10.1016/j.paid.2018.09.036

Woolf, A.-L. (2019). Poisoned All Blacks, living Elvis and the fake moon landing: What some Kiwis believe. Retrieved from https://www.stuff.co.nz/science/112877029/poisoned-all-blacks-elvis-and-the-moonlanding-what-some-kiwis-believe-in

Zappone, C. (2019). Russian propaganda 'very likely' stoking 5G health fears in Australia: expert claims. Retrieved from https://www.smh.com.au/world/oceania/russianpropaganda-stoking-5g-health-fears-in-australia-20190916-p52rmc.html 
MOTIVATIONAL CORRELATES OF CONSPIRACY THEORIES 36

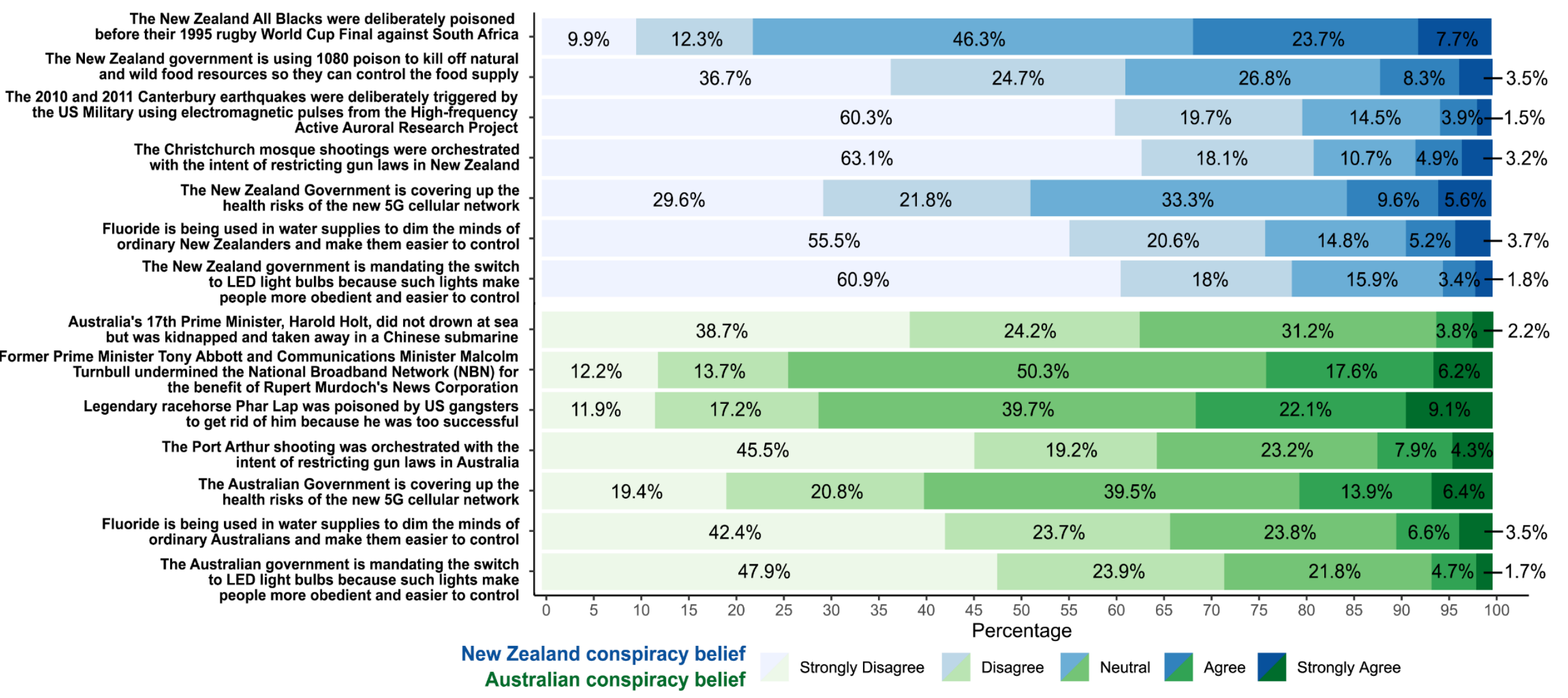

Figure 1. Percentage of New Zealand and Australian levels of Belief in Local Conspiracy Theories

Note: Blue bars represent New Zealand $N=754$. Green bars represent Australia $N=1,011$. 
MOTIVATIONAL CORRELATES OF CONSPIRACY THEORIES 37

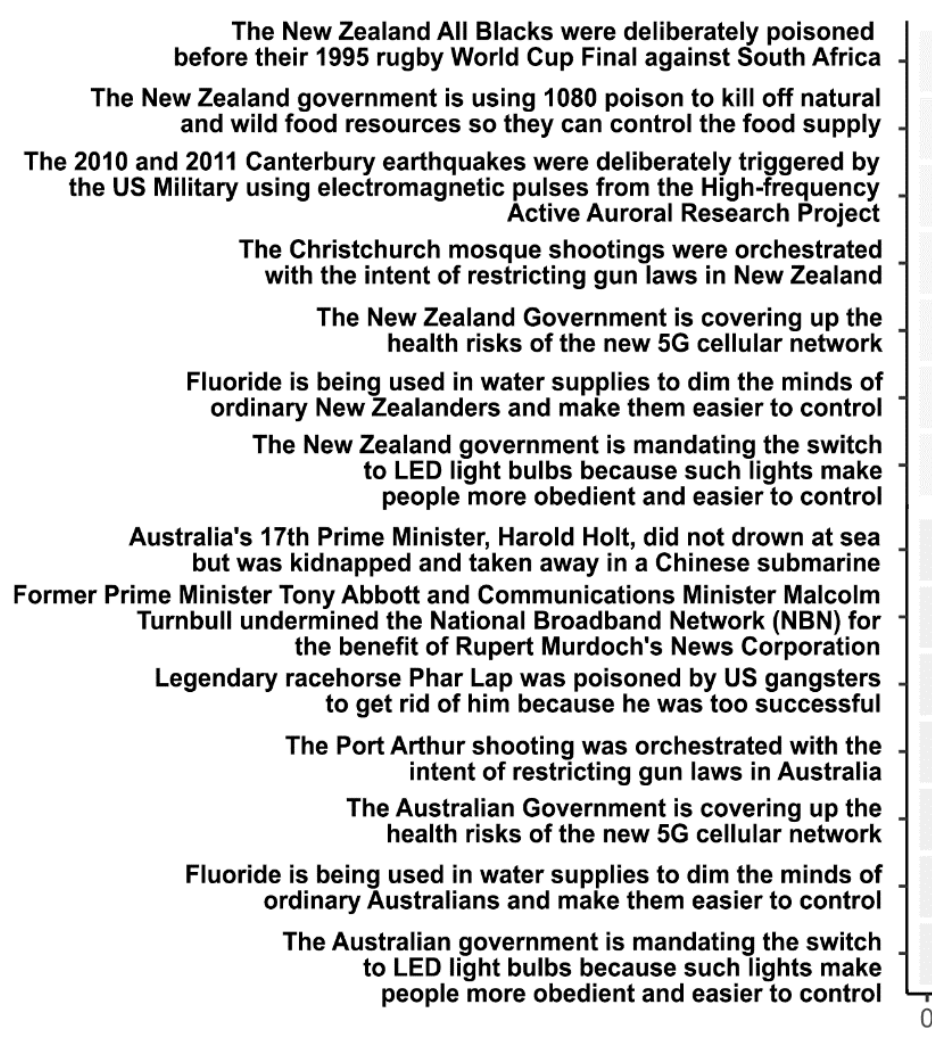

$9.9 \%$

\begin{tabular}{|c|c|c|c|c|}
\hline $12.3 \%$ & $46.3 \%$ & & & $7.7 \%$ \\
\hline \multirow[t]{3}{*}{$36.7 \%$} & $24.7 \%$ & $26.8 \%$ & & \\
\hline & $60.3 \%$ & $19.7 \%$ & $14.5 \%$ & $3.9 \%$ \\
\hline & $63.1 \%$ & $18.1 \%$ & $10.7 \%$ & $.9 \%$ \\
\hline $29.6 \%$ & $21.8 \%$ & $33.3 \%$ & $9.6^{\circ}$ & $5.6 \%$ \\
\hline
\end{tabular}

$29.6 \%$

\begin{tabular}{|c|c|c|c|}
\hline $55.5 \%$ & $20.6 \%$ & $14.8 \%$ & $5.2 \%$ \\
\hline $60.9 \%$ & $18 \%$ & $15.9 \%$ & $3.4 \%$ \\
\hline
\end{tabular}

\begin{tabular}{|c|c|c|c|c|}
\hline & $38.7 \%$ & $24.2 \%$ & $31.2 \%$ & $3.8 \%-$ \\
\hline $12.2 \%$ & $13.7 \%$ & $50.3 \%$ & $17.6 \%$ & $6.2 \%$ \\
\hline $11.9 \%$ & $17.2 \%$ & $39.7 \%$ & $22.1 \%$ & $9.1 \%$ \\
\hline & $45.5 \%$ & $19.2 \%$ & $23.2 \%$ & $7.9 \% \quad 4.3 \%$ \\
\hline
\end{tabular}

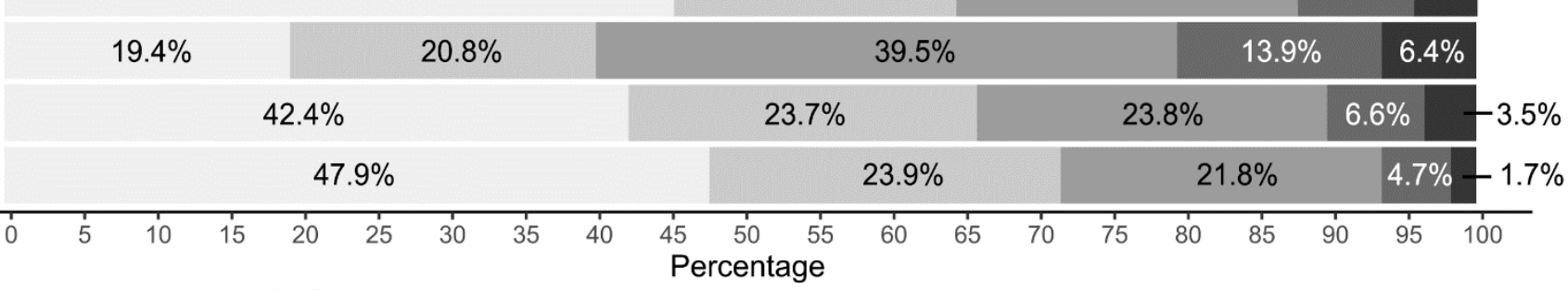

Australian conspiracy belief New Zealand conspiracy belief

Strongly Disagree

Disagree

Neutral

Agree

Strongly Agree

Figure 1a. Percentage of New Zealand and Australian levels of Belief in Local Conspiracy Theories

Note: New Zealand $N=754$. Australia $N=1,011$. 


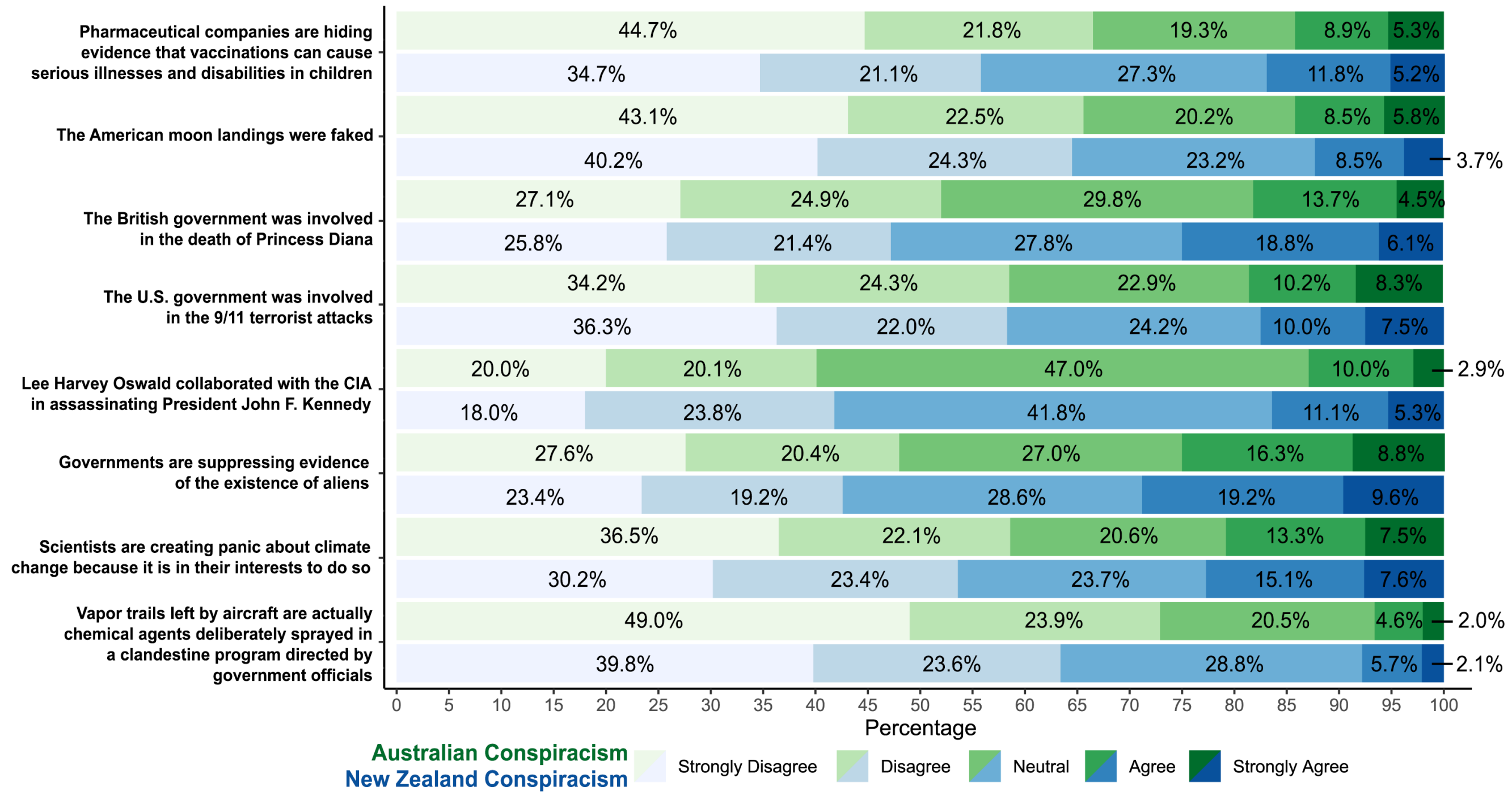

Figure 2. Percentage of Australian and New Zealand levels of Belief in International Conspiracy Theories

Note: Green bars represent Australia $N=1,011$. Blue bars represent New Zealand $N=754$. 
MOTIVATIONAL CORRELATES OF CONSPIRACY THEORIES 39

Pharmaceutical companies are hiding

evidence that vaccinations can cause serious illnesses and disabilities in children

The American moon landings were faked

The British government was involved in the death of Princess Diana

The U.S. government was involved in the 9/11 terrorist attacks

Lee Harvey Oswald collaborated with the CIA in assassinating President John F. Kennedy

Governments are suppressing evidence of the existence of aliens

Scientists are creating panic about climate change because it is in their interests to do so

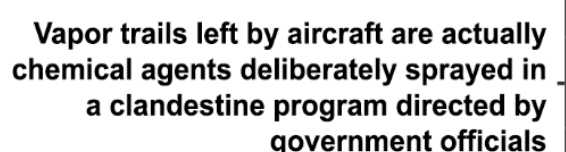
government officials

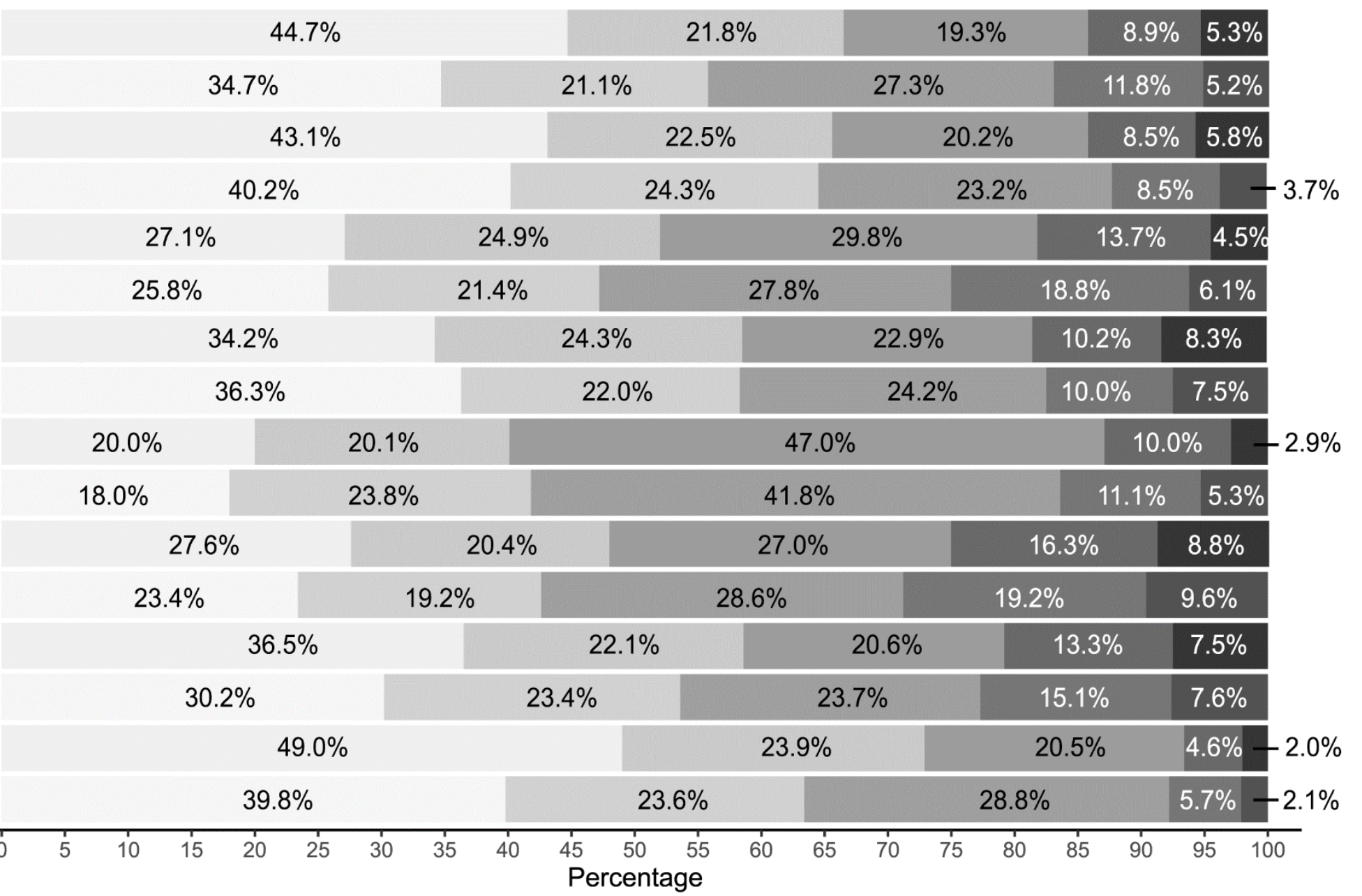

Australian conspiracy belief New Zealand conspiracy belief
Strongly Disagree
Neutral

Figure 2a. Percentage of Australian and New Zealand levels of Belief in International Conspiracy Theories

Note: Top of each pair represent Australia $N=1,011$, bottom of each pair represent New Zealand $N=754$. 
Table 1. Demographic Characteristics of Australian and New Zealand Samples.

\begin{tabular}{|c|c|c|}
\hline & $\begin{array}{l}\text { Australia } \\
(n=1011)\end{array}$ & $\begin{array}{c}\text { New Zealand } \\
(n=754)\end{array}$ \\
\hline & Percentage & Percentage \\
\hline Gender: Female & 50.94 & 50.00 \\
\hline \multicolumn{3}{|l|}{ Area } \\
\hline Metropolitan / Urban & 79.23 & 82.23 \\
\hline Rural & 19.68 & 17.24 \\
\hline Remote & 1.09 & 0.53 \\
\hline \multicolumn{3}{|l|}{ Annual income } \\
\hline Less than $\$ 10,000$ & 8.21 & 5.70 \\
\hline$\$ 10,000-\$ 19,999$ & 9.59 & 9.68 \\
\hline$\$ 20,000-\$ 29,999$ & 13.45 & 17.37 \\
\hline$\$ 30,000-\$ 39,999$ & 8.70 & 7.29 \\
\hline$\$ 40,000-\$ 49,999$ & 8.61 & 8.49 \\
\hline$\$ 50,000-\$ 59,999$ & 8.61 & 9.15 \\
\hline$\$ 60,000-\$ 69,999$ & 7.02 & 7.29 \\
\hline$\$ 70,000-\$ 79,999$ & 4.75 & 5.84 \\
\hline$\$ 80,000-\$ 89,999$ & 4.85 & 4.38 \\
\hline$\$ 90,000-\$ 99,999$ & 3.56 & 4.11 \\
\hline$\$ 100,000-149,999$ & 8.90 & 7.29 \\
\hline More than $\$ 150,000$ & 3.46 & 2.25 \\
\hline Rather not to say & 10.39 & 11.14 \\
\hline \multicolumn{3}{|l|}{ Education level (highest attained) } \\
\hline High school not completed & 11.93 & 12.33 \\
\hline High school graduate, or the equivalent & 28.03 & 22.65 \\
\hline Advanced Diploma & 15.21 & 16.09 \\
\hline Bachelors degree, Graduate Diploma and Certificate & 31.51 & 35.52 \\
\hline Postgraduate Diploma and Certificate, Bachelor Honours Degree & 5.07 & 8.04 \\
\hline Masters degree & 6.76 & 4.69 \\
\hline \multirow[t]{2}{*}{ Doctorate degree } & 1.39 & 0.80 \\
\hline & $M(S D)$ & $M(S D)$ \\
\hline Age (years) & $47.22(18.06)$ & $47.67(17.94)$ \\
\hline Importance of religion/spirituality & $3.70(2.19)$ & $3.74(2.25)$ \\
\hline \multicolumn{3}{|l|}{ Political Ideology } \\
\hline Economic & $3.85(1.20)$ & $3.96(1.20)$ \\
\hline Social & $3.98(1.31)$ & $4.13(1.37)$ \\
\hline
\end{tabular}

Note. Weighted $N$ for all variables. Four participants identifying as gender non-binary omitted from analyses for each sample. Five cases of unspecified education level not reported for AU; eight unspecified education level cases for NZ. All percentages reported are valid percentages. Range for age is 18-90 for AU and 18-96 years for NZ. Range for importance of religion/spirituality is $1=$ Not at all to $7=$ Extremely. Political ideology is $1=$ Extremely Conservative, $2=$ Very Conservative, $3=$ Somewhat Conservative, $4=$ Neither Conservative nor Progressive, 5=Somewhat Progressive, 6=Very Progressive, 7=Extremely Progressive. 
Table 2. Intercorrelations and Descriptive Statistics Between Local and International Conspiracism, Trust, Anomie, Disillusionment with Government, Analytical Thinking, and Economic and Social Political Self-Placement for Australian (above the diagonal) and New Zealand (below the diagonal) Samples.

\begin{tabular}{|c|c|c|c|c|c|c|c|c|c|}
\hline & 1 & 2 & 3 & 4 & 5 & 6 & 7 & 8 & 9 \\
\hline 1. Local conspiracies & - & $.782 *$ & $-.189 *$ & $.311 *$ & $.294^{*}$ & $-.169 *$ & $-.102 *$ & $-.131 *$ & $.173^{*}$ \\
\hline 2. International conspiracies & $.730^{*}$ & - & $-.279 *$ & $.368 *$ & $.279 *$ & $-.127 *$ & $-.107 *$ & $-.165^{*}$ & $.167 *$ \\
\hline 3. Trust in Others & $-.305^{*}$ & $-.368^{*}$ & - & $-.360 *$ & $-.380^{*}$ & .012 & -.018 & .024 & $.108^{*}$ \\
\hline 4. Anomie & $.348^{*}$ & $.393^{*}$ & $-.366^{*}$ & - & $.516^{*}$ & $-.084 *$ & .049 & -.013 & .059 \\
\hline 5. Disillusionment in government & $.327^{*}$ & $.308^{*}$ & $-.291 *$ & $.335^{*}$ & - & -.009 & $.143^{*}$ & $.125^{*}$ & $-.084 *$ \\
\hline 6. Analytic Thinking & $-.141^{*}$ & $-.130^{*}$ & .012 & -.002 & -.032 & - & .006 & .023 & -.060 \\
\hline 7. Economic Political Ideology & $-.122 *$ & -.064 & -.014 & .032 & $-.176^{*}$ & .039 & - & $.689^{*}$ & $-.175^{*}$ \\
\hline 8. Social Political Ideology & $-.175^{*}$ & $-.148^{*}$ & .045 & -.058 & $-.304 *$ & .034 & $.628^{*}$ & - & $-.207 *$ \\
\hline 9. Religion/Spirituality & $.234^{*}$ & $.188^{*}$ & .055 & -.020 & .068 & $-.100 *$ & $-.137 *$ & $-.161 *$ & - \\
\hline Australian $M(S D)$ & $\begin{array}{c}2.38 \\
(0.73)\end{array}$ & $\begin{array}{c}2.40 \\
(0.84)\end{array}$ & $\begin{array}{c}4.42 \\
(1.24)\end{array}$ & $\begin{array}{c}4.46 \\
(1.24)\end{array}$ & $\begin{array}{c}4.31 \\
(1.62)\end{array}$ & $\begin{array}{c}1.45 \\
(1.10)\end{array}$ & $\begin{array}{c}3.85 \\
(1.20)\end{array}$ & $\begin{array}{c}3.98 \\
(1.31)\end{array}$ & $\begin{array}{c}3.70 \\
(2.19)\end{array}$ \\
\hline New Zealand $M(S D)$ & $\begin{array}{c}2.07 \\
(0.73)\end{array}$ & $\begin{array}{l}2.29 \\
(0.82)\end{array}$ & $\begin{array}{c}4.68 \\
(1.28)\end{array}$ & $\begin{array}{c}4.18 \\
(1.23)\end{array}$ & $\begin{array}{c}3.52 \\
(1.68)\end{array}$ & $\begin{array}{c}1.63 \\
(1.09)\end{array}$ & $\begin{array}{c}3.96 \\
(1.20)\end{array}$ & $\begin{array}{c}4.13 \\
(1.37)\end{array}$ & $\begin{array}{c}3.74 \\
(2.25)\end{array}$ \\
\hline $\begin{array}{l}\text { Mean Difference } \\
\text { between samples } \\
\text { Cohen's d }(95 \% \text { CI) }\end{array}$ & NA & $\begin{array}{c}-.132 \\
(-.227,-.038)\end{array}$ & $\begin{array}{c}.207 \\
(.335, .146)\end{array}$ & $\begin{array}{c}-.228 \\
(-.323,-.134)\end{array}$ & $\begin{array}{c}-.478 \\
(-.574,-.383)\end{array}$ & $\begin{array}{c}.160 \\
(.066, .255)\end{array}$ & $\begin{array}{c}.092 \\
(-.003, .186)\end{array}$ & $\begin{array}{c}-.111 \\
(-.206,-.017)\end{array}$ & $\begin{array}{c}.018 \\
(-.076, .112)\end{array}$ \\
\hline
\end{tabular}

Note: Conspiracy belief ranges from 1 to 5 . All other variables are range from 1 to 7 . Lower scores reflect lower levels of the construct. For political ideology items, lower scores indicate Conservative self-placement and higher scores indicate Progressive self-placement. Australia $N=1,011$, New Zealand $N=754$.

$* p<.01$. 
Table 3. Hierarchical Multiple Regressions Predicting Australian and New Zealand Local Conspiracy Belief with Psychological Motives after Controlling for Demographic Predictors.

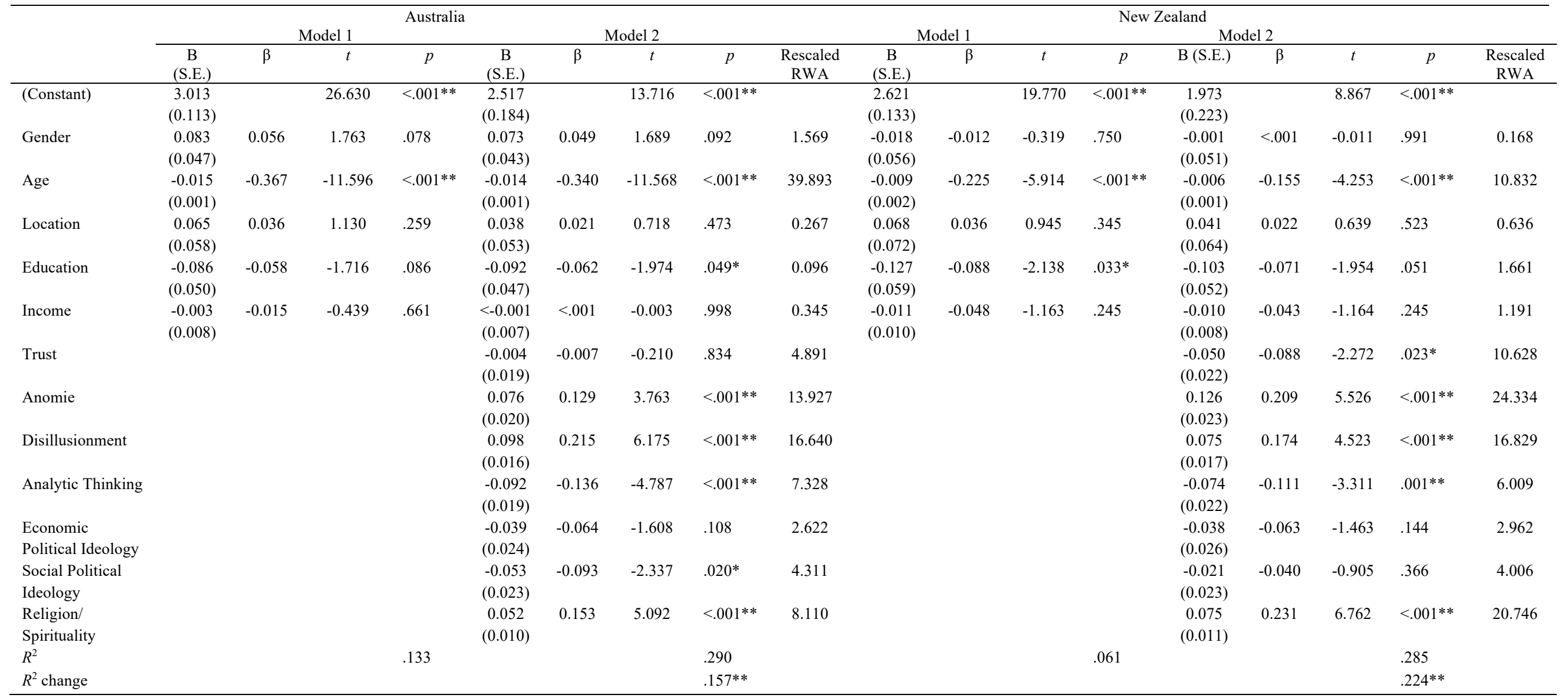

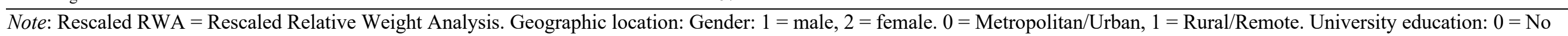

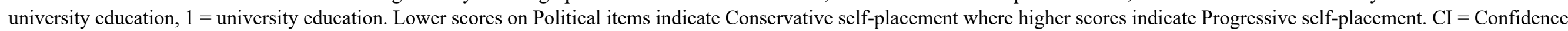
Interval. Australia $N=904$, New Zealand $N=662$.

$* * p<=.01 . * p<.05$ 
Table 4. Hierarchical Multiple Regressions Predicting Combined Australian and New Zealand Belief in International Conspiracies with Psychological Motives after Controlling for Demographic Predictors.

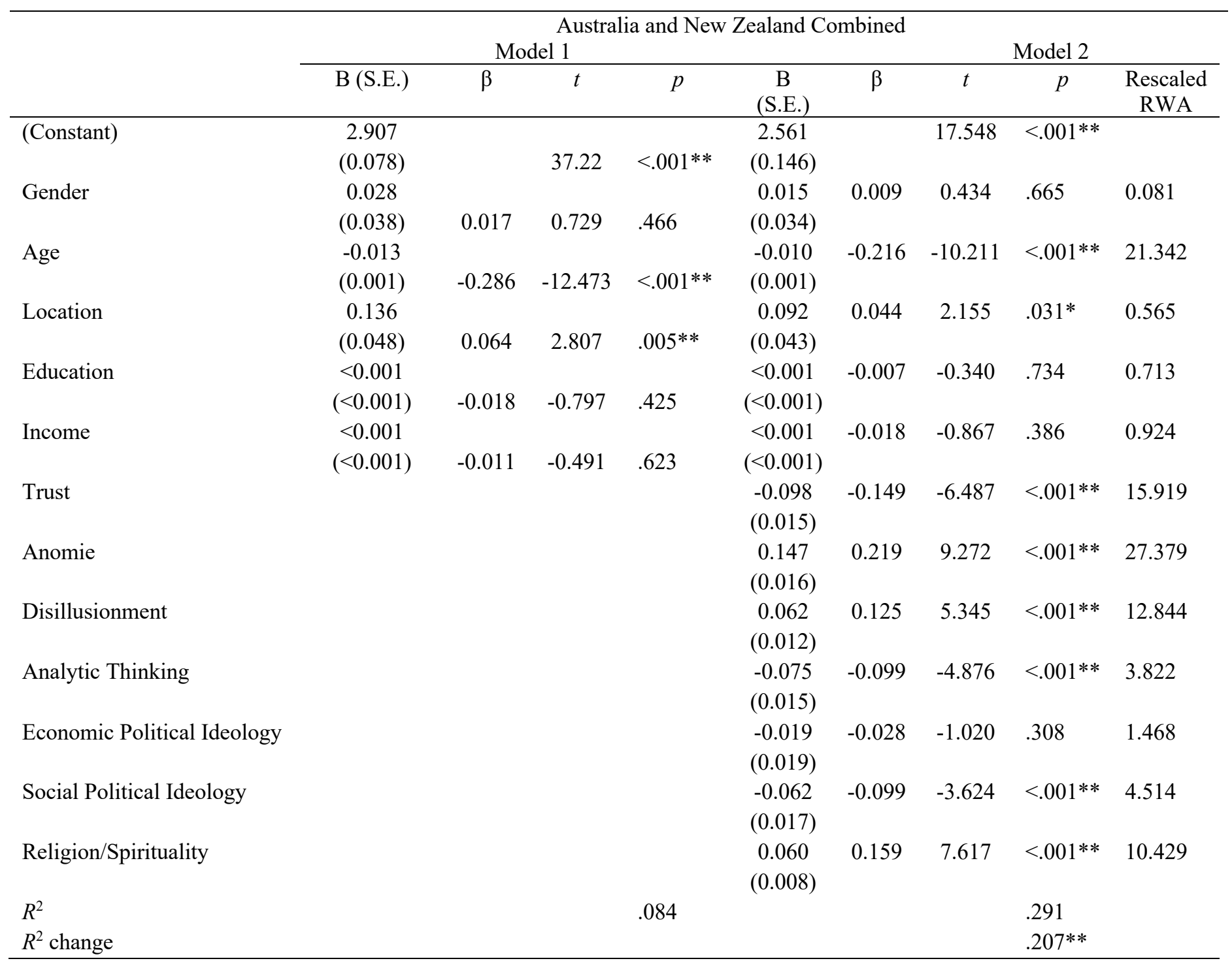

Note: Rescaled RWA = Rescaled Relative Weight Analysis. Geographic location: Gender: 1 = male, $2=$ female. $0=$ Metropolitan/Urban, $1=$ Rural/Remote. University education: $0=$ No university education, 1 $=$ university education. Lower scores on Political items indicate Conservative self-placement where higher scores indicate Progressive self-placement. $\mathrm{CI}=$ Confidence Interval. $N=1765$.

$* * p<.01$. 